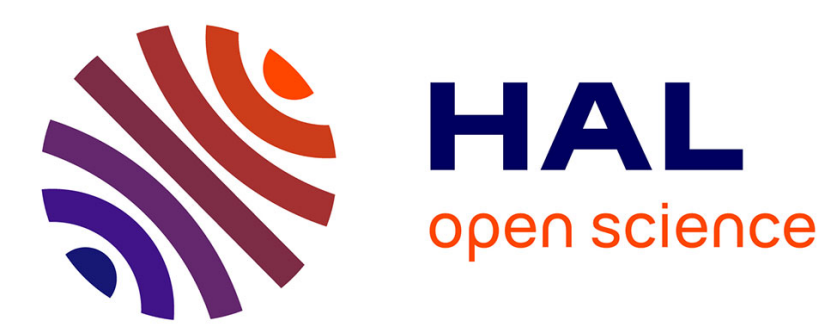

\title{
PHOTOLITHOGRAPHIC PROCESSES IN AMORPHOUS SEMICONDUCTORS
}

\author{
M. Janai
}

\section{To cite this version:}

M. Janai. PHOTOLITHOGRAPHIC PROCESSES IN AMORPHOUS SEMICONDUCTORS. Journal de Physique Colloques, 1981, 42 (C4), pp.C4-1105-C4-1114. 10.1051/jphyscol:19814241 . jpa00220873

\section{HAL Id: jpa-00220873 https://hal.science/jpa-00220873}

Submitted on 1 Jan 1981

HAL is a multi-disciplinary open access archive for the deposit and dissemination of scientific research documents, whether they are published or not. The documents may come from teaching and research institutions in France or abroad, or from public or private research centers.
L'archive ouverte pluridisciplinaire HAL, est destinée au dépôt et à la diffusion de documents scientifiques de niveau recherche, publiés ou non, émanant des établissements d'enseignement et de recherche français ou étrangers, des laboratoires publics ou privés. 


\title{
PHOTOLITHOGRAPHIC PROCESSES IN AMORPHOUS SEMICONDUCTORS
}

\author{
M. Janai \\ Dept. of Physics, Technion, Haifa 32000, Israet.
}

\begin{abstract}
Various photolithographic processes in a wide class of amorphous semiconductor films have been proposed and demonstrated in the past decade. The special features of the photosensitive amorphous semiconductor materials - non graininess, inorganic chemistry, deposition from the vapor phase and durability in dry and wet etchants - make them attractive photoresists for sub-micron fabrication of integrated circuits and integrated optics devices. The photolithographic processes in amorphous semiconductors can be classified according to four photosensitive effects: [1] light enhanced chemical reactivity; [2] photodissolution of metals, [3] light enhanced vaporization and [4] light induced crystallization. For each of these processes the mechanism, the sensitivity and the resolution are described with reference to published data, and its merit for the fabrication process of integrated circuits is discussed. Applications in which the photosensitive materials can serve as the final micro-component are emphasized.
\end{abstract}

1. Introduction. - In the process of photolithography a photosensitive material changes its solubility in certain etchants according to the amount of irradiation incident upon it. Relief patterns formed in thin layers of high resolution photolithographic materials can be used as components in integrated optics or integrated electronic devices, or may serve as protective masks in the processing of the substrate on which they are deposited. The latter process has received much attention in recent years, since it is the basis of the microfabrication technology for integrated electronic circuits (1). The ever-increasing demands of the microelectronic industry require photolithographic materials (photoresists) with sub-micron resolution, high sensitivity, good adhesion to the common substrates used in microelectronics, and high resistance to a wide class of dxy (plasma) and wet (chemical) etchants. other important requirements include uniform photoresist thickness over areas up to $5^{\prime \prime}$ in diameter, consistency of etch rate, high differential solubility of the exposed and unexposed portions of the film, good step coverage, low pinhole density and minimum undercut. The photosensitive material should be non-contaminating, hard (non sticky), and should not change dimensions after exposure. For applications such as ion implantation, the material should have high aspect ratio and high stopping power; for use with e-beam or with $x$-ray lithography the material should have high atomic number, and to all these are added, of course, the requirements for process simplicity and low cost.

Thin films of certain amorphous semiconductors have many of the properties wanted for microelectronic photoresists, as well as those useful for integrated-optics components. Amorphous chalcogenide films, for example, dissolve easily in alkaline solutions but are very resistant to aqueous solution of $\mathrm{H}_{2} \mathrm{SO}_{4}, \mathrm{HF}, \mathrm{H}_{3} \mathrm{PO}_{4}$ and $\mathrm{HCl}$ which are used for $\mathrm{SiO}_{2}, \mathrm{Si}_{3} \mathrm{~N}_{4}$ and $\mathrm{Si}$ patterning, and thus they can serve as etching masks. Amorphous chalcogenide semiconductors are also useful for integrated optics applications, since they have low transmission losses in the infrared and high acousto-optic coefficients $(2,3)$.

In this paper we describe the mechanisms and the performance of four different photolithographic processes in amorphous semiconductor films. The processes are [1] light enhanced chemical reactivity, [2] photodissolution of metals, [3] 1ight enhan- 
ced vaporization, and [4] photocrystallization. These processes may be sub-classified into positive or negative processes. In a positive process the irradiated portion of the material becomes dissolvable, while in a negative process the irradiated part becomes etch-resistant. Two important parameters in the characterization of a photolithographic process are the resolution and the sensitivity. The resolution is sometimes determined by projecting an image of a test pattern and examining the smallest resolvable etched line width $(4,5)$. Another way to determine the resolution is to measure the modulation amplitude of a sinosoidal relief pattern as a function of line pair density (MTF) $(6,7)$. The other parameter - the sensitivity - is usually derived from the $\gamma$ curve. The $\gamma$ curve is the fractional etched thickness (for a positive process) or the fractional remaining thickness (for a negative process) of the photosensitive material, as a function of the exposure $I \cdot t(I=$ irradiated intensity, $t=$ exposure time). The sensitivity is defined as the reciprocal exposure (in $\left(\mathrm{J} / \mathrm{cm}^{2}\right)^{-1}$ ) which corresponds to the midpoint on the $\gamma$ curve. The particular MTF and $\gamma$ curve of a given photolithographic process depend not only on the properties of the photosensitive material, but also on its initial thickness, on its development procedure and on other process parameters. Nevertheless, these two curves are useful in the evaluation of photolithographic systems, as will be seen below.

2. Mechanisms of photolithographic processes in amorphous semiconductors. -

2.1 Light Enhanced Chemical Reactivity (LECR). - The effect of LECR appears in thin films of chalcogenide semiconductor gisses. Upon irradiation, the solubility rate of the chalcogenide film in its natural solvent (usually an alkaline solution) is changed. Keneman (8) has reported that films of $\mathrm{As}_{2} \mathrm{~S}_{3}$, approximately $1 \mu \mathrm{m}$ thick, which were exposed to the $5145 \AA$ line of an Ar+ laser, dissolved in $0.01 \mathrm{~N} \mathrm{NaOH}$ solution at a rate of $5 \AA / \mathrm{sec}$, while a freshly evaporated film has an etch rate of $8 \AA / \mathrm{sec}$ (a negative photolithographic process). Shirakawa et a1. (9) studied $\mathrm{As}_{2} \mathrm{~S}_{3}$ and other Asbased amorphous chalcogenide compounds. The films were exposed to $3 \mathrm{~J} / \mathrm{cm}^{2}$ radiation from a mercury arc lamp, and they observed a subsequent increase of up to $25 \%$ in the etch rate by $1 \mathrm{~N} \mathrm{NaOH}$ (a positive photolithographic process). Chang et al. (6.10.11) confirmed Keneman's results, and showed that the effect is exhibited also in $\mathrm{CF}_{4}$ plasma etching with an etching-rate ratio of $1: 1.8$ between the exposed and unexposed portions of the film (12). Utsugi and Zembutsu (13) studied various compositions of the As-S-Ge-Se system. They report etch-rate ratios of $1: 0.52,1: 0.38$ and 1:1.6 in $1.5 \mu$ thick films with exposure $15.3 \mathrm{~J} / \mathrm{cm}^{2}$. Both negative and positive photolithographic processes are obtained, depending on the material composition.

Another group of chalcogenides $-\mathrm{Ge}_{x} \mathrm{Se}_{1-x}$ was studied by Yashikawa et a1. $(4,14$, 15) and by Singh et al. (16). The first found that photoexposed $\mathrm{Ge}_{25} \mathrm{Se}_{75}$ dissolves 1.18 times faster than a heat-treated film. Heat treatment was performed just below the glass temperature, for $5 \mathrm{~min}$. The second group reported that the etching rate difference can be increased by up to $30 \%$ if the film is obliquely deposited at $80^{\circ}$.

Some insight into the mechanism of the LECR process is obtained from the work of Gurevich et al. (17). They pointed out that the etching rate varies with the variation of the refractive index of the film, and that record-and-erase cycles produced by irradiation and heat-treatment are observed in the behaviour of both the refractive index and the etch rate. Hou and Chang (6) have shown that the difference in the LECR of $\mathrm{As}_{2} \mathrm{~S}_{3}$ is proportional to the absolute value of the photoinduced change of the refractive index. Similar results were obtained by Zembutsu et al. for other chalcogenide compositions (18).

The experimental evidence suggests that the LECR is closely related to the reversible and irreversible variations of the values of the optical constants of amorphous chalcogenide semiconductors. The irreversible variations of the optical constants of thin evaporated chalcogenide films have been attributed to cross linking and polymerization of the evaporated molecules, a similar effect to that of post-deposition heat-treatment (19). A cross-1inking process is the basis of most common negative polimeric photoresists and can explain the increased etch resistance of exposed or heat-treated films relative to freshly-evaporated films $(6,10-12,16)$. The effect of irradiation on heat-treated (annealed) films, however, is not so clear. Tanaka has shown (20) that reversible structural transformations also accompany the 
reversible photodarkening and bleaching caused respectively by irradiation and heattreatment. He suggested a bi-stable structural model to explain this behavior (21, 22). As implied above, structural transformations may also cause changes in chemical solubility. Street and Mott (23) proposed the charged defect states ( $D^{+} D^{-}$) model which was further developed by Kastner et al. (24). (the VAP mode1). Recently this has been specifically applied to the optical transformations and thermal bleaching of amorphous chalcogenide thin films (25). This mode1, of electronic nature, is not likely to explain the LECR phenomenon nor the optical transformations themselves. The $\mathrm{D}^{*} \mathrm{D}^{-}$model was originally proposed in order to solve problems associated with ESR and the photoluminescence behavior in amorphous chalcogenides. As pointed out by Tanaka (22), it is unlikely that one model with a single spectrum of energy states can explain two phenomena (e.g. light induced ESR and reversible photodarkening) which have such different kinetics and temperature dependence. Yet it is not clear that the model proposed by Tanaka hinself of the origin of the optical transformations can be applied to the LECR, since no clear correlation was found between the optical transformations and LECR. For example, it was reported that two slightly different material compositions result in opposite-sign LECR 1ithographic processes, while the values of the optical constants of both materials vary in the same way upon exposure $(13,18)$. More experimental and theoretical work may be needed to resolve this problem.

Resolution as high as $5400 \mathrm{l} / \mathrm{mm}$ has been demonstrated for LECR of $\mathrm{As}_{2} \mathrm{~S}_{3}$ by MTF measurements (6). Figure 1 shows a relief pattern formed in thermally grown $\mathrm{SiO}_{2}$ by

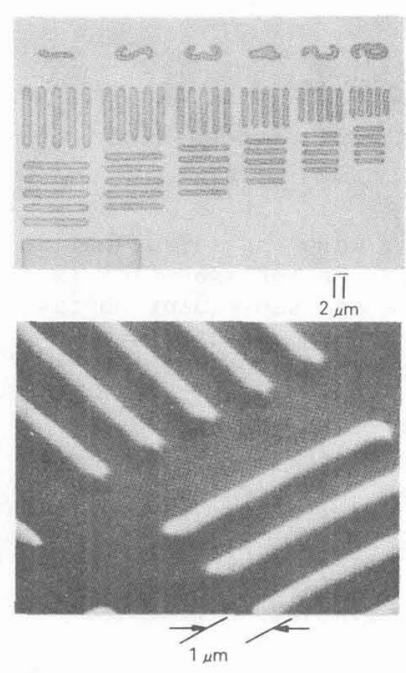

Fig. 1. -Pattern etched in $\mathrm{SiO}_{2}$ through a $\mathrm{Ge}_{25} \mathrm{Se}_{75}$ protective mask formed by positive LECR(4).
LECR of $\mathrm{Ge}_{2} \mathrm{Se}_{73}$ (4). As seen from the figure, 1 m resolution is obtained. Curves $(j)$ and $(k)$ of figure 2 demonstrate the $\gamma$ of the LECR process in as-evaporated $\mathrm{As}_{2} \mathrm{~S}_{3}$ and in heat-treated $\mathrm{Ge}_{25} \mathrm{Se}_{75}$, respectively. The etchrate contrast is poor, and so is the sensitivity $\left(1 /\left(6 \mathrm{~J} / \mathrm{cm}^{2}\right)\right)$. LECR was used by Keneman to intensify phase holograms (8), and by Sakai and Utsugi (26) to

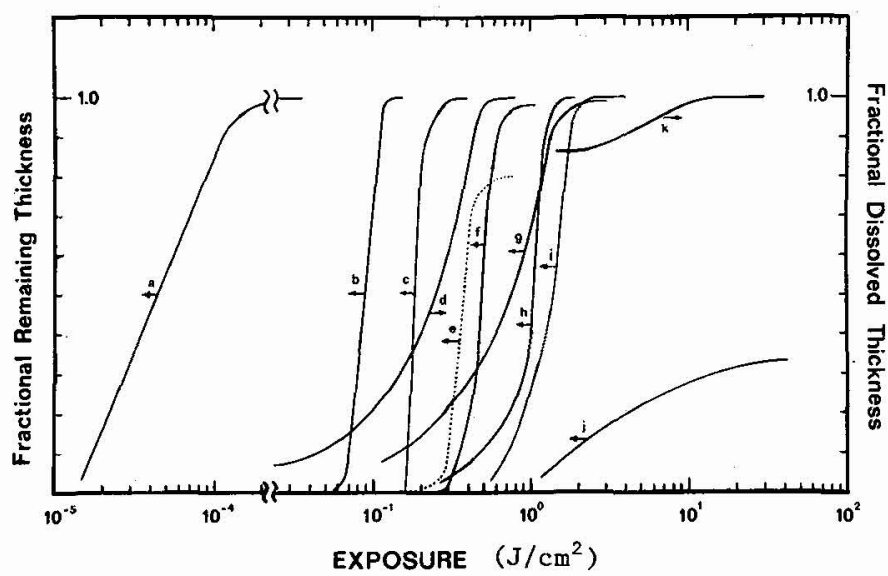

Fig. 2.-Exposure characteristics of some amorphous semiconductor photoresists. (a) $0.1 \mu \mathrm{m}$ silver halide over $0.5 \mu \mathrm{m} \mathrm{As} \mathrm{As}_{3}$ (with photographic developement) (29). (b) 0.01 $\mu \mathrm{m}$ silver $\left(\mathrm{AgNO}_{3}\right.$ ) over $0.27 \mu \mathrm{m} \mathrm{Ge}{ }_{25} \mathrm{Se}_{75}$ (plasma etching) (28). (c) $0.01 \mu \mathrm{m}$ silver $\left.(\mathrm{AgNO})_{3}\right)$ over $0.28 \mu \mathrm{m} \mathrm{Ge} \mathrm{Ge}_{15} \mathrm{Se}_{85}$ (e-beam exposure,5kV) (27). (d) $5000 \AA \mathrm{As}_{2} \mathrm{~S}_{3}$ (LEV, $1 \mathrm{~atm} . \mathrm{O}_{2}, 180$ ${ }^{\circ} \mathrm{C}, 0.1 \mathrm{~mW} / \mathrm{cm}^{2}$, microscope slide substrate)(38). (e) CVD amorphous silicon (photocrystallization, estimated) (45). (f) $0.01 \mu \mathrm{m}$ silver $\left(\mathrm{AgNO}_{3}\right.$ ) over $\mathrm{Ge}_{10} \mathrm{Se}_{90}(4)$. (g) silver (evaporated) over $1.1 \mu \mathrm{m} \mathrm{As} \mathrm{s}_{17} \mathrm{~S}_{79} \mathrm{Te}_{4}(9)$. (h) $0.01 \mu \mathrm{m}$ silver (AgNO $)_{3}$ over $0.46 \mu \mathrm{m}$ $\mathrm{Ge}_{25} \mathrm{Se}_{75}(15)$. (i) $0.02 \mu \mathrm{m} \mathrm{AgCl}$ (evaporated) over $0.3 \mu \mathrm{m} \mathrm{As}_{2} \mathrm{~S}_{3}$ (x-ray exposure) (11). (j) $0.3 \mu \mathrm{m}$ as-evaporated $\mathrm{As}_{2} \mathrm{~S}_{3}$ (LECR, negative process) (11). (k) $0.77 \mathrm{~mm}$ heat-treated $\mathrm{Ge}_{25} \mathrm{Se}_{75}$ (LECR, positive process) (15). The $\gamma$ curve of a common polimeric photoresist ( $A 2$ 1350) lies between curves (b) and (c). 
copy holograms. However, the present low contrast and low sensitivity of the LECR process in amorphous chalcogenides seem to prohibit its use in practical systems.

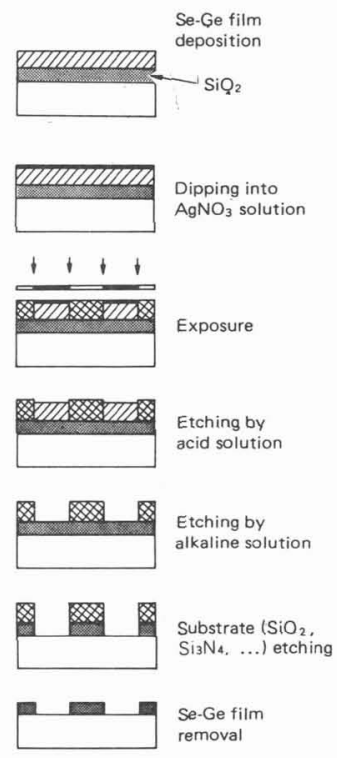

2. 2 Photodissolution of Metals (PD). - The photolithographic process $\bar{i}$ in amorphous semiconductors which has received most attention so far is the one based on the drastic reduction of chemical solubility of amorphous chalcogenide thin films in alkaline solutions upon photodissolution of metals in them. The photosensitive system in the PD process, schematically depicted in fig. 3, comprises of a thin silver layer $(0.01 \sim 0.05 \mu \mathrm{m})$ deposited over (or underneath) a somewhat thicker layer $(0.1 \sim 0.5 \mu \mathrm{m})$ of evaporated or sputtered amorphous chalcogenide semiconductor such as $\mathrm{As}_{2} \mathrm{~S}_{3}$ or $\mathrm{Ge}_{25} \mathrm{Se}_{75}$. Light irradiation (26), $\mathrm{x}$ ray (11) or e-beam exposure (27) cause the silver to dissolve in the chalcogenide, and render it insoluble in alkaline solutions. The silver of the unexposed regions can be removed by an acid solution such as $\mathrm{HNO}_{3}-\mathrm{HCl}-\mathrm{H}_{2} \mathrm{O}$, and the unexposed chalcogenide is removed by an alkaline solution. The remaining film has an excellent protection ability against most chemical etchants (4). After the etching of the substrate it can be removed by hot $\mathrm{H}_{2} \mathrm{SO}_{4}$. Following exposure, the relief pattern can be developed also by $\mathrm{CF}_{4}$ plasma. High etch-rate ratios of $1: 210$ for $\mathrm{As}_{2} \mathrm{~S}_{3}$ (12) and $1: 370$ for $\mathrm{Ge}_{25} \mathrm{Se}_{75}$ (28) have been reported.

The necessary silver layer can be applied by vacuum evaporation, by dipping the chalcogenide film in $\mathrm{AgNO}_{3}$ solution (15) or by evaporation of a silver-halide film such as $\mathrm{AgBr}_{0.97} \mathrm{I}_{0.03}$ on the chalcogenide film (29). In the later case the silver-halide is exposed, and the latent image is photographically developed. Photodissolution is then performed by flood-illumination. The use of silver halide and subsequent photographic development greatly enhances the sensitivity of the process, as can be seen from curve (a) in figure 2. The sensitivity of other silver-chalcogenide combinations under 1ight, $x$-ray and e-beam exposure is demonstrated by curves (b), (c), (f), $(\mathrm{g})$, (h) and (i) of fig. 2. It should be noted that a process which uses silver as part of the photosensitive system may be particularly attractive for $x$-ray or e-beam lithography due to the high stopping power of silver for these radiations. The use of $\mathrm{AgNO}_{3}$ or, even better, a silver-halide film as the source of silver has an advantage over an evaporated silver layer, since the evaporated silver may start the reaction with the chalcogenide during evaporation due to the kinetic energy of the evaporated silver atoms (thermal-doping) or due to the light irradiation from the evaporation fillament (photo-doping).

Fig. 4 demonstrates the results of the etching of thermally grown $\mathrm{SiO}_{2}$ through a protective mask of silver-photodoped $\mathrm{Ge}_{25} \mathrm{Se}_{75}$. Resolution of 0.3 um has been demonstrated by e-beam exposure $(27,29)$. However, the ultimate resolution of the process may be at the $50 \AA$ range, as recently demonstrated by Yoshikawa et a1. (30).

The steep $\gamma$ curves of the photodissolution process (Fig. 2 (b), (c), (f), (g)) suggest that a kind of a threshold effect is associated with this process. Indeed, Kolwicz and Chang (11) observed that only a very thin ( $800 \AA$ ) photodoped layer on top of an undoped ( $5000 \AA$ ) chalcogenide layer is sufficient to give etch protection to the undoped chalcogenide as well as to the $\mathrm{SiO}_{2}$ underneath. This observation is also confixmed by the results of Yoshikawa et al. (28) for plasma etching. It appears that the excellent performance of this photoresist in the anisotropic plasma etchant is partially because a "cup" is formed under the thin photodoped layer, which then protects the underlying substrate (1i). The critical exposure needed to form the top photodoped layer of this cup is the threshold exposure which is derived from the mid-points of the various $\gamma$ curves of fig. 2 . 
In the following we shall concentrate on the $\mathrm{Ag} / \mathrm{As}_{2} \mathrm{~S}_{3}$ system which has been studied more than most other systems. The similarity of the PD effect in all the chalcogenide amorphous thin films suggests that the results ought to be applicable al so to other compositions. Recent models $(32,33)$ of the PD phenomenon have been based on the $\mathrm{D}^{+} \mathrm{D}^{-}$(23) or on the VAP (24) models of electronic energy states in amorphous chalcogenides, and on the results of photovoltage measurments. Ishikawa (32) suggested that the light deionnizes the charged defect states $\left(D^{+}+D^{-}+h \nu \rightarrow 2 D^{\circ}\right)$. The neutralized defect states $D^{\circ}$ trap electrons which are thermally released by the silver atoms, and become stable $D^{-}$states. The $D^{-}$states then electrostatically attract the $\mathrm{Ag}^{+}$ions into the amorphous chalcogenide film. Tanaka (22) has tied the PD phenomenon together with the photostructural transformations which are observed in pure amorphous chalcogenide films. According to him, neither of these phenomena can be explained by the $\mathrm{D}^{+} \mathrm{D}^{-}$model.

We have recently pointed out (36) that according to published spectral data $(34,35)$ the photoexcitation in the PD phenomenon must take place inside the silver, below the silver-chalcogenide interface. To mention three of the reasons for this conclusion, let us first note that Inoue et a1. (35) and Kolwicz et al. (11) reported that the front of the photodissolved silver stops propagating once the elemental silver on the surface has been consumed. Secondly, the first authors obtained a higher sensitivity of the PD phenomenon in $\mathrm{As}_{2} \mathrm{~S}_{3}$ for photon energies below the optical band gap when the light came from the silver side than when the light came from the chalcogenide side of the sandwich junction. This is hardly possible if the light which comes from the silver side has to pass the highly reflecting silver-air and silver-chalcogenide barriers, whereas the light which comes from the chalcogenide side has to pass only one low reflection chalcogenide-air barrier. Thirdly, while the spectral sensitivity for illumination from the chalcogenide side does show similarity to the optical absorption spectra of the semiconductor $(34,35)$, the spectral sensitivity for illumination from the silver side over the same spectral range is almost flat. We have shown that in the case of illumination from the chalcogenide side the similarity of the PD sensitivity to the chalcogenide absorptance is not because more photons are observed in the chalcogenide, but because more photons are coupled into the silver following optical matching of the extinction coefficients of the silver and the chalcogenide. If, indeed, the active light is absorbed entirely in the silver, there should not be any correlation between the PD process and other light enhanced phenomena in amorphous chalcogenide semiconductors.

After consideration of the atomic percentages of photodissolved silvervs. chalcogenide film $(11,31,37)$ we concluded (36) that a new glassy phase of composition nearly that of $\mathrm{As}_{4} \mathrm{Ag}_{5} \mathrm{~S}_{6}$ is formed by a light enhanced solid-state reaction. The action of the light is to reduce the kinetic barrier of this reaction, which is thermodynamically favorable. There are indications that a material of the composition As- $\mathrm{Ag}-\mathrm{S}$ should be insoluble in alkaline solusions, and hardly etchable in most acids (36). The formation of such an etch-resistant compound on top of the exposed metalchalcogenide $\mathrm{film}$ is probably the clue to the action of this photoresist.

Optimization of the relative silver-chalcogenide filn thicknesses for chalcogenide compositions other than $\mathrm{As}_{2} \mathrm{~S}_{3}$ should be made according to thermodynamics and chemical considerations which take into account the stability and the relative atomic density of the newly formed phases. Better understanding of the PD mechanism and correct choice of the composition of the photoreacting layers might make this inorganic system the next generation photoresist in sub-micron lithography. 
2.3 Light Enhanced Vaporization (LEV). - The effect of LEV has been observed in the

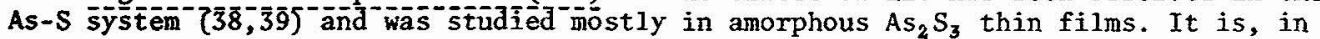
fact, a light enhanced oxidation reaction followed by the thermal evaporation of the volatile reaction products :

$$
\mathrm{As}_{4} \mathrm{~S}_{6}+3 \mathrm{O}_{2} \text { hy } \mathrm{As}_{4} \mathrm{O}_{6}++3 \mathrm{~S}_{2} \uparrow .
$$

This reaction results in a positive photolithographic process (Fig. 5). The vaporization rate is generally constant with time, and almost independent of film thickness (40). Thus the thicker the film, the longer the exposure needed to evaporate it. Curve (d) of fig. 2 shows the exposure required to remove a $5000 \AA \mathrm{As}_{2} \mathrm{~S}_{3}$ film from a microscope slide substrate by LEV under 1 atm $\mathrm{O}_{2}, 0.1 \mathrm{~mW}$ irradiation at wavelength $\lambda=4350 \AA$, and a temperature of $180^{\circ} \mathrm{C}$. The sensitivity of the process at low light levels is relatively high, but it degrades with increasing light levels because of sub-linear dependence of the process on 1 ight intensity. LEV rates up to $40 \mathrm{~A} / \mathrm{sec}$ have been demonstrated. The dark vaporization rate is usually $2 \sim 3$ orders of magnitude lower than the LEV rate, so that high contrast relief profiles can be obtained.

In experiments to measure the MTF of the LEV process in $\mathrm{As}_{2} \mathrm{~S}_{3}$ the resolution limit was found to be in the $1 \mu \mathrm{m}$ range (7). However, this seems to have resulted from limitations in the method of measurment, and it will be shown below that the ultimate resolution of the LEV process might be in the range of $200 \AA$. Fig. 6 shows a fused silica slide which was etched through an $\mathrm{As}_{2} \mathrm{~S}_{3}$ protective mask produced by LEV (5). The photograph was taken with an interference objective, which demonstrates an etch depth of $1.2 \mu \mathrm{m}$. No attempt was made to minimize pinholes or ensure uniform and complete LEV exposure for this particular demonstration.

The LEV process in amorphous $\mathrm{As}_{2} \mathrm{~S}_{3}$ films seems particularly promising (2) in those applications such as integrated optics, where 3 -dimensional micro-features are required. Using this process, a two dimensional multitone picture can be transformed to a 3-dimensional relief pattern by projecting its image onto $\mathrm{As}_{2} \mathrm{~S}_{3}$. Since LEV is a real time photolithographic process with no subsequent development, it can be monitored and controlled interferometrically to a high precision. We have used it to form 3D optical waveguides and grating couplers, and it can be used easily to form

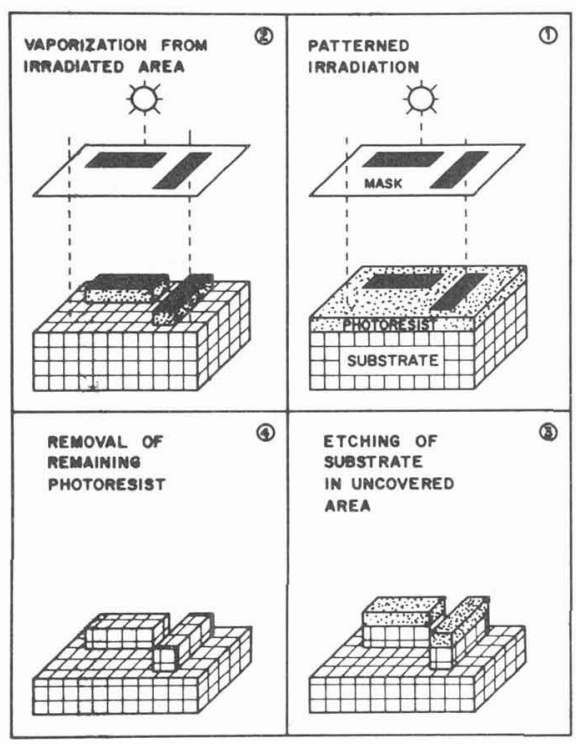

Fig. 5.-Schematic illustration of the LEV lithographic process. 3D microlenses. A particularly interesting application is the production of tapered couplers from single mode waveguides to single mode optical fibers (41). By precise

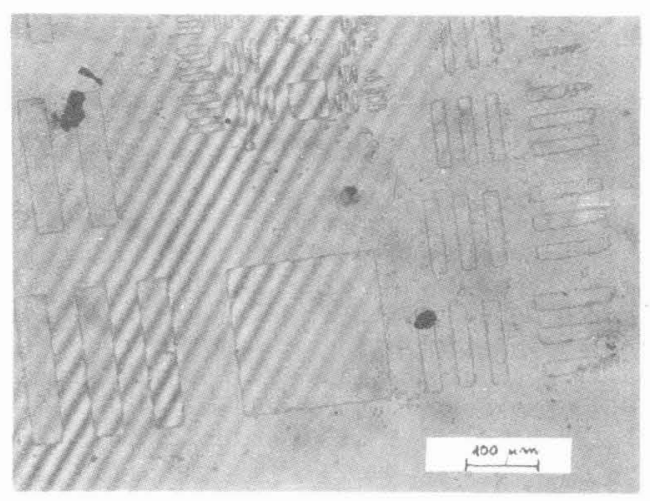

Fig. 6.-White light interferogram of a test pattern etched in a fused silica substrate through an $\mathrm{As}_{2} \mathrm{~S}_{3}$ mask formed by LEV. 


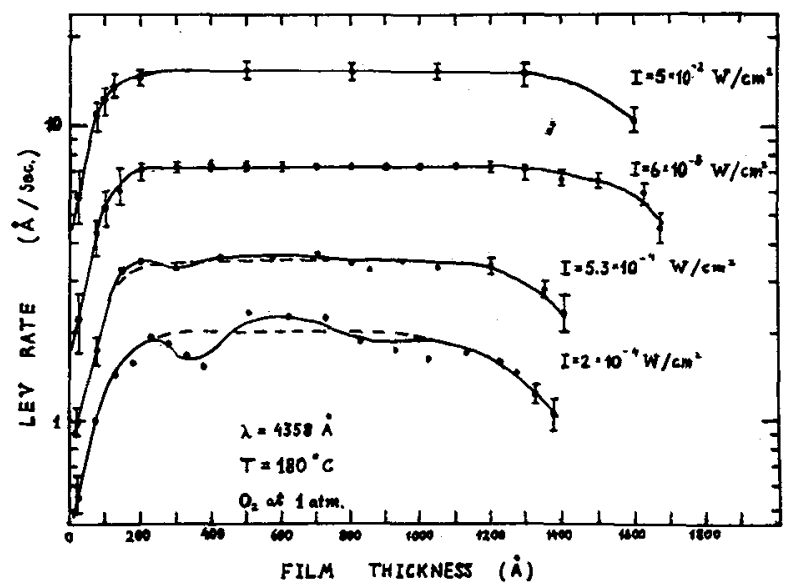

Fig. 7.-LEV rate vs thickness of thinning films of $\mathrm{As}_{2} \mathrm{~S}_{3}$ for four light levels. The extreem points to the right on each curve represent the initial film thickness (about $1500 \AA$ ). The oscilations of the data at low light levels are due to multiple-reflections interference. control of the shape, slope and thickness of a tapered $\mathrm{As}_{2} \mathrm{~S}_{3}$ buffer layer between a waveguide (e.g. $\mathrm{LiNbO}_{3}$ ) and a silica fiber the light can be coupled out of the waveguide and into the fiber. Preliminary tests of these ideas revealed'a few problems. One of them was that during the LEV process the $\mathrm{As}_{2} \mathrm{~S}_{3}$ surface developed roughness on the scale of $0.1 \sim 0.3 \mathrm{~mm}$. This causes light scattering and rapid attenuation of the guided light wave. The mechanism by which this roughness develops is not yet clear to us.

The model for LEV of $\mathrm{As}_{2} \mathrm{~S}_{3}$ that has evolved $(40,42$, $43)$ is based on the correlation between photoconductivity and LEV behaviour. As we have shown elsewhere $(42,43)$, both the temperature and the time (kinetics) dependences of these two phenomena are similar. Thus is has been suggested that the LEV rate is controlled by the flow of photocarriers to the $\mathrm{As}_{2} \mathrm{~S}_{3}-\mathrm{O}_{2}$ interface. The active photocarriers are produced within a layer of width $(\mathrm{D} \tau)^{1 / 2}$ below the $\mathrm{As}_{2} \mathrm{~S}_{3}-\mathrm{O}_{2}$ interface, where $D$ is the diffusion coefficient of the charge carriers and $\tau$ its decay time constant. Fig. 7 shows the thickness dependence of the LEV rate of $\mathrm{As}_{2} \mathrm{~S}_{3}$ for four different light levels. As can be seen, the LEV rate is almost constant until a layer of only $175 \AA$ of $\mathrm{As}_{2} \mathrm{~S}_{3}$ has remained. Only then the LEV rate drops down. This indicates that photons absorbed deeper than $175 \AA$ below the $\mathrm{As}_{2} \mathrm{~S}_{3}-\mathrm{O}_{2}$ interface do not reach the surface and do not contribute to the LEV oxidation reaction. Indeed, from the known values of the charge decay time and the mobility, the value of $(D \tau)^{1 / 2}$ was estimated to be $200 \AA$ (42).

Figure 7 indicates another interesting feature of the LEV process. If one calculates the number of photons absorbed in the active layer of $175 \AA$ for $\lambda=4358 \AA$ $\left(\alpha(\lambda=4358 \AA)=7 \cdot 10^{4} \mathrm{~cm}^{-1}\right)$ and compares it with the number of molecules evaporated from the surface, one gets an amplification factor of 40 (e.g. 40 vaporizing molecules per one surface photocarrier). To date we have not resolved the exact chain of surface reactions which result in the LEV process, and it it not yet clear which is the rate limiting step at which the surface photocarrier is required.

As to the performance of the LEV Iithographic process, the resultant amplification factor together with the fact that $(\mathrm{D} \tau)^{4 / 2} \simeq 175 \AA$ suggest that this figure should represent the ultimate resolution of the process. One may reach an amplification factor of a few orders of magnitude when one photocarrier is sufficient to vaporize a volune containing about 1000 molecules, $i . e \sim \sim(30 \AA)^{3}$. Besides its potential practical application, the LEV process seems to be an interesting tool in the study of electronic processes in amorphous $\mathrm{As}_{2} \mathrm{~S}_{3}$. LEV is probably the only process discussed in this paper which is tied directly to electronic processes in amorphous semiconductors, and is definitly controlled by excess charge carriers. It seems to be unrelated to the photostructural transformations or to the light induced ESR discussed in section 2.1 above, since the LEV rate reaches its maximum at temperatures $\left(\sim 195^{\circ} \mathrm{C}\right)$ beyond the annealing temperature of the other effects and beyond the glass temperature of $\mathrm{As}_{2} \mathrm{~S}_{3}$. We a1so found strong evidence that the LEV rate may be controlled by contact potentials and internal electric fields in the $\mathrm{As}_{2} \mathrm{~S}_{3} \mathrm{films}$, a phenomenon which deserves further study $(40)$. 


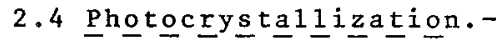

We have recently initiated in our laboratory a study of photocrystallization lithography. This work is still in its infancy, but preliminary results have shown great promise. The process we study is the direct photolithography of amorphous silicon films, which are patterned (annealcrystallized) by laser irradiation of a Q-switched ruby laser through a photographic mask (44). Fig. 8 shows a direct negative print of an image produced by photocrystallization on a $4600 \AA$-thick film. The bright regions of the photograph correspond to the amorphous silicon regions which are almost opaque to visible light The dark regions correspond to the polycrystalline laser annealed regions, which have a higher transmittance $(44,45)$. Besides the interesting features of this photographic process for holographic and digital optical data recording applications, it may find use in photolithography. A recent paper reports an etch rate ratio of $1: 5$ of the polycrystalline (thermally annealed) versus amorphous silicon. The difference in etch rates seems to increase with a decrease in the deposition temperature of the amorphous silicon. So far we have demonstrated $\sim 1$ m width lines in CVD amorphou silicon films on fused silica substrates, and we are currently studying the MTF and the $\gamma$ curves of this process. If the potential of this photolithographic process materializes, it will be possible to pattern directly the CVD silicon and form the connecting circuity and the gates in MOS devices with no need for an additional oxidation and photoresist step. The amorphous silicon can also serve as an inorganic photoresist in the fabrication of other steps in the integrated circuit. CVD silicon has excellent step coverage features and its photolithographic use is clean and may have high merit for other processing steps in the IC manufacturing technology.

The mechanism of pulsed laser annealing is still under intensive investigation by many groups (47), although not in relation to imaging. From our own preliminary results we can not yet determine whether the process takes place through a solidstate re-ordering reaction or a melting

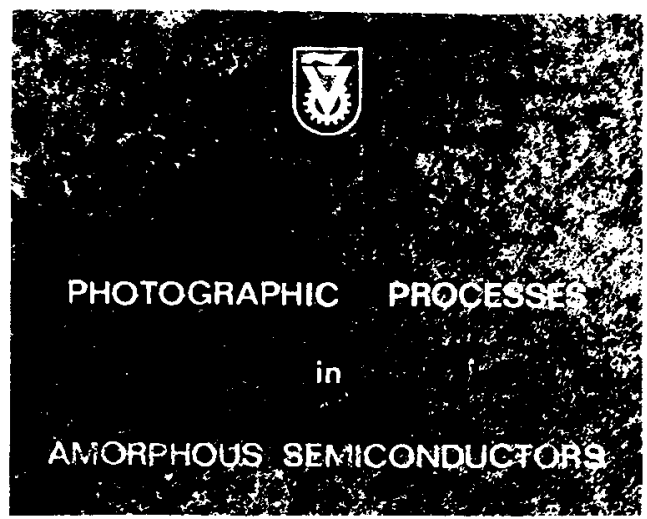

Fig. 8.-Image produced by Q-switched laser photocrystallization of amorphous silicon (44). The dark regions in the photograph correspond to the laser anneal-crystallized portions of the film. The speckles are due to beam nonuniformity. and crystallizing of the silicon film. However, the high lateral resolution which we obtain seems to support the first possibility.

3. Summary and Conclusions. - Four photo Tithographic processes - LECR, PD, LEV and photocrystallization were discussed. Despite the natural tendency towards unified models, we come to the conclusion that each of these processes is controlled by a basically different mechanism. The LECR has the kinetics of the photostructural transformations and a similar temperature dependence, so that these two effects seem to be connected. The PD effect does not seem to be related to the electronic excitations in amorphous semiconductors since the excitation takes place in the metal. The released photoexcited charge carriers, though, may be trapped temporarily on the photodissolved amorphous side of the metal-semiconductor junction. The LEV is due to photoexcitation in the semiconductor, but has no relation to the

photostructural transformations. It is more associated with the effect of charge migration and surface recombination of the photoexcited charge carriers. The photocrystallization in amorphous silicon seems to be a re-ordering solid-state transfor. mation, yet to be studied. 
From the practical point of view, PD lithography seems to show great promise for plasma processing of sub-micron features produced by $\mathrm{x}$-ray or e-beam as well as deep UV radiation. LEV in $\mathrm{As}_{2} \mathrm{~S}_{3}$ may find use in the production of integrated optics devices. The photocrystallization of amorphous silicon has still to be studied before conclusions can be drawn. But, undoubtedly, the success of this process may simplify and improve considerably the manufacturing of integrated circuits.

The author expresses his gratitude to Prof. S.G. Lipson for critical reading of the text, to Dr. A. Yoshikawa for supplying figures 1 and 4 , and to Mrs. M. Janai for her indispensable help throughout the preparation of this manuscript.

References. -

(1) See, for example, Physics Today, "Special Issue: Microscience", $\underline{32}$ (11) (1979) pp. $25-51$.

(2) ZEMBUTSU S. and FUKUNISHI S., Appl. Opt. 18 (1979) 393; KURITA S. and SETO Y., Optics \& Quantum Electr. 12 (1980) 179; WĀTTS R.K. and McINTIER J.R., AppI. Opt. 14 (1975) 575, TANAKA K. and ODAJIMA A., App1. Phy. Lett. 38 (1981) 481.

(3) MAYDAÑ D., IEEE J. QE 6 (1970) 15; OHMACHI Y., J. App1. Phys. $4 \overline{4}(1973) 3928$.

(4) YOSHIKAWA A., NAGAI H. and MIZUSHIMA Y., Supp1. Japan, J. App1. Phys. 16 (1977) 67.

(5) JANAI M. and RUDMAN P.S., Photogr. Sci. Eng. 20 (1976) 234.

(6) HOU T.W. and CHANG M.S., App1. Opt. 18 (1979) 1753.

(7) JANAI M., OSCAR S., LIPSON S.G. and RUUDMAN P.S., Opt. Lett. 2 (1978) 51.

(8) KENEMAN S.A., Thin Solid Films 21 (1974) 281.

(9) SHIRAKAWA T., SHIMIZO I., KOKADŌH. and INOUE E., Photogr. Sci. Eng. 19 (1975) 139.

(10) CHANG M.S. and HOU T.W., Thin Solid Films 55 (1978) 463.

(11) KOLWICZ K.D. and CHANG M.S., J. Electrochem. Soc. 127 (1980) 135.

(12) CHANG M.S. and CHEN J.T., Appl. Phys. Lett. 33 (1978) 892.

(13) UTSUGI Y. and ZEMBUTSU S., App1. Phys. Lett. $\overline{27}$ (1975) 508.

(14) NAGAI H., YOSHIKAWA A., TOYOSHIMA Y., OCHI 0. and MIZUSHIMA Y., App1. Phys. Lett. 28 (1976) 145.

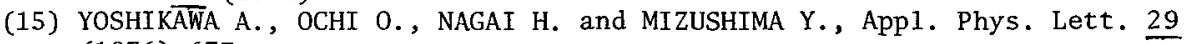
(1976) 677.

(16) SINGH B., RAJAGOPALAN S. and CHOPRA K.L., J. Appl. Phys. 51 (1980) 1768.

(17) GUREVICH S.B., ILYASHENKO N.N., KOLOMIETS B.T., LYUBIN V.M. and SHILO V.P., Phys. Stat. Sol. (a) 26 (1974) K 127.

(18) ZEMBUTSU S., UTSUGI Y. and SAKAI T., Opt. Commun. 17 (1976) 28.

(19) de NEUFVILLE J.P., MOSS S.C. and OVSHINSKY S.R., J. Non-Cryst. Solids $13(1973 / 74) 191$.

(20) TANAKA K., App1. Phys. Lett. 26 (1975) 243.

(21) TANAKA K., HAMAKAWA H. and II ZTMA S., Proc. 7th Int. Conf. on Amorphous and Liquid Semiconductors, (ed.) W.E. SPEAR (CICL, U. of Edinburgh 1977) p. 787.

(22) TANAKA K., J. Non-Cryst. Solids 35-36 (1980) 1023.

(23) STREET R.A. and MOTT N.F., Phys. Rev. Lett. 35 (1975) 1293.

(24) KASTNER M., ADLER D. and FRITZSCHE H., Phys. Rev. Lett. 37 (1976) 1504.

(25) AVERIANOV V.L., KOLOBOVE A.V., KOLOMIETS B.T. and LYUBIN V.M., Phys. Stat. Sol. (a) 57 (1980) 81 .

(26) SAKUMA H., SHIMIZU I., KOKADO H. and INOUE E., Proc. 3rd Conf. Solid State Devices, Tokyo, 1971, Supp1. Oyo Buturi 41 (1972) 76.

(27) YOSHIKAWA A., OCHI O., NAGAI H. and MIZUSHIMA Y., App1. Phys. Lett. 31 (1977) 161.

(28) YOSHIKAWA A., OCHI O. and MIZUSHIMA Y., AppI. Phys, Lett. 36 (1980) 107.

(29) MASTERS J.I., GOLDBERG G.M. and LAVINE J.M., IEEE Electron. Device Lett. EDL-1 (1980) 61 ; LAVINE J.M., MASTERS J.I. and DAS A., IEEE Int. Electron. Device Meeting (Washington D.C. Dec. 1980) p. 420. 
(30) YOSHIKAWA A., HIROTA S., OCHI 0., TAKEDA A. and MIZUSHIMA Y., Japan. J. Appl. Phys. 20 (1981) 481.

(31) de-NEUFVILLE J.P., in Amorphous and Liquid Semiconductors, (ed.) J. Stuke and W. Brenig (Taylor \& Francis, London 1974) p. 1351.

(32) ISHIKAWA R., Solid State Commun. 30 (1979) 99 ; ISHIKAWA R. and KIKUCHI M., J. Non-Cryst. Solids 35-36 (1980) 1061 .

(33) KOKADO H., SHIMIZU I., TATSUNO T. and INOUE E., J. Non-Cryst. Solids 21 (1976) 225.

(34) GOLDSCHMIDT D. and RUDMAN P.S., J. Non-Cryst. Solids 22 (1976) 229.

(35) INOUE E., KOKADO H., and SHIMIZU I., Suppl, J. Japan. Soc, Appl. Phys. 43 (1974) 101.

(36) JANAI M., "The photodissolution of silver in amorphous $\mathrm{As}_{2} \mathrm{~S}_{3}$ thin films" Subm. to Phys. Rev. Lett. (1981).

(37) GOLDSCHMIDT D., BERNSTEIN T., and RUDMAN P.S., Phys. Stat. Sol. (a) 41 (1977) 283.

(38) JANAI M. and RUDMAN P.S., in ref. 31 p. 425.

(39) JANAI M. and RUDMAN P.S., U.S. patent 3,999,990.

(40) JANAI M., RIESS I. and RUDMAN P.S., Surface Science 74 (1978) 13.

(41) HSU H.P. and CHANG W.S.C., Progress report on coupling methods in prospective single mode fiber-integrated optics systems, Navy Contract N00014-76-C-0796, Washington University, St. Louis MO,1976.

(42) JANAI M. and RUDMAN P.S., Phys. Stat. Sol. (a) 42 (1977) 729.

(43) JANAI M., AFIF A., RIESS I. and RUDMAN P.S., in ref. 21 p. 575.

(44) JANAI M., "Optical recording in amorphous silicon films" submitted for publication to App1. Phys. Lett. (May 1981).

(45) JANAI M., ALLRED D.D., BOOTH D.C., and SERAPHIN B.O., Solar Energy MateriaIs 1 (1979) 11 .

(46) BOXALL B.A., Solid-State Electronics 20 (1977) 873.

(47) e.g. DeHESS L. and YARON G., Indust. $\overline{R e s}$. Devel. (November 1979) p. 141 ; WOOD R.F. and GILES G.E., App1. Phys. Lett. 38(1981) 422. 